
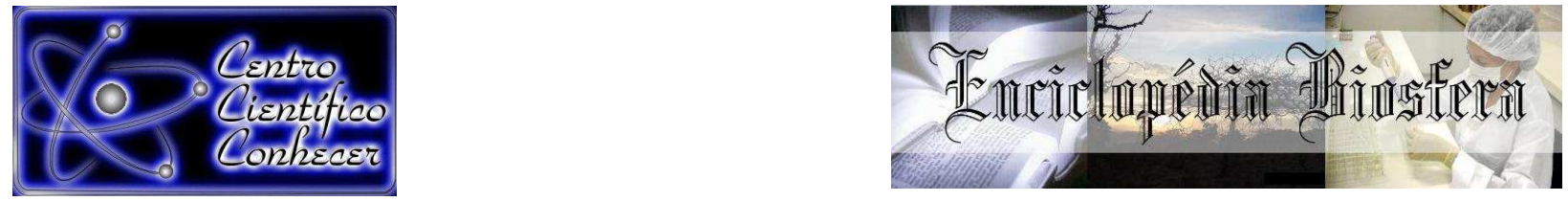

\title{
RESPOSTAS FISIOLÓGICAS DE DUAS LINHAGENS DE FRANGO DE CORTE INDUSTRIAL CRIADOS SOB CONDIÇÃO DE INVERNO AMAZÔNICO
}

\section{Ramon Reis Menzel ${ }^{1}$, Henrique Jorge de Freitas ${ }^{2}$, Edcarlos Miranda Sousa ${ }^{2}$, Julio Veras de Almeida e Silva ${ }^{3}$}

${ }^{1}$ Engenheiro Agrônomo formado pela Universidade Federal do Acre, Rio Branco Acre - AC;

${ }^{2}$ Professor Doutor do Programa de Pós-graduação em Produção e Sanidade Animal Sustentável na Amazônia Ocidental da Universidade Federal do Acre, Rio Branco AC;

${ }^{3}$ Doutorando do Programa de Pós-graduação em Produção e Sanidade Animal Sustentável na Amazônia Ocidental da Universidade Federal do Acre, Rio Branco Acre-AC (julio-verass@hotmail.com);

Recebido em: 02/10/2017 - Aprovado em: 21/11/2017 - Publicado em: 05/12/2017 DOI: 10.18677/EnciBio_2017B60

\begin{abstract}
RESUMO
O objetivo deste trabalho foi avaliar as respostas fisiológicas de duas linhagens de frango de corte industrial (Cobb e Ross) sob as condições de temperatura do Acre para determinar a viabilidade da produção dessas aves no Estado. O experimento foi conduzido nas instalações experimentais do Setor de Avicultura da Universidade Federal do Acre, durante o inverno Amazônico. Foram criados 280 pintos de um dia até 42 dias de idade, de ambas as linhagens. Os pintos foram distribuídos nas unidades experimentais, separados por sexo, com ração e água à vontade. A ração fornecida foi à base de fubá de milho e farelo de soja, atendendo às necessidades nutricionais em cada etapa de desenvolvimento. Uma vez por semana foram coletados os dados para avaliação das respostas fisiológicas da ave selecionada de cada unidade experimental. Os dados coletados foram de temperatura cloacal, frequência respiratória e temperatura da superfície corporal (cabeça, crista, face, pescoço, peito, sob a asa, perna e penas). Para a análise do conforto térmico, foi utilizado um delineamento em blocos casualizados com sete repetições, em que cada bloco consistia no sexo das aves. Concluiu-se que as linhagens de frangos de corte estudadas, criadas sob condições de inverno Amazônico possuem respostas fisiológicas semelhantes.
\end{abstract}

PALAVRAS-CHAVE: ambiência, avicultura, conforto térmico.

\section{PHYSIOLOGICAL RESPONSES OF FREE-RANGE BROILERS REARED IN THE AMAZON WINTER CONDITIONS}

\begin{abstract}
The objective of this work was to evaluate the physiological responses of two industrial chicken lines (Cobb and Ross) under the temperature conditions of Acre to determine the viability of the production of these birds in the State. The experiment
\end{abstract}


was conducted at the experimental facilities of the Aviculture Sector of the Federal University of Acre, during the Amazonian winter. One hundred and eighty one day old chicks up to 42 days old were raised from both strains. The chicks were distributed in the experimental units, separated by sex, with ration and water at will. The feed provided was based on corn meal and soybean meal, meeting the nutritional needs at each stage of development. Once a week data were collected to evaluate the physiological responses of the selected bird from each experimental unit. The data collected were cloacal temperature, respiratory rate and body surface temperature (head, crest, face, neck, chest, under wing, leg and feathers). For the thermal comfort analysis, a randomized block design with seven replications was used, in which each block consisted of the birds' sex. It was concluded that the strains of broiler chickens reared under Amazonian winter conditions have similar physiological responses.

KEYWORDS: ambience, poultry, thermal comfort.

\section{INTRODUÇÃO}

O Brasil tem se consagrado na produção avícola e também tem desempenhado papel fundamental no consumo de frangos, ocupando lugar de destaque no mercado internacional. Rodrigues et al. (2014) afirmam que essa cadeia produtiva é muito competitiva. No entanto, cada vez mais é necessário criar técnicas para adaptação de animais em diferentes regiões, principalmente em locais de altas temperaturas, até mesmo com relação às oscilações térmicas registradas ao longo do ano.

Deve-se tentar evitar manejos inadequados, para que o custo de produção não aumente, diminua a produção e a perda de lotes. Os frangos de corte têm demonstrado suscetibilidade aos fatores ambientais, com ênfase especial à temperatura. De acordo com Lopes et al. (2015) o principal efeito da temperatura é causar estresse nas aves, afetando consequentemente o desempenho zootécnico e o rendimento de carcaça, ocorrendo resultados insatisfatórios na produção animal.

Os frangos de corte respondem de maneira diferente aos fatores de estresse variando entre uma e outra linhagem. Para Macari et al. (2002), as respostas podem variar em função da idade do animal, da aclimatação e do sexo. Portanto, os frangos machos tendem a ser mais susceptíveis ao calor do que as fêmeas, devido ao seu maior peso e melhor conversão alimentar.

Na Amazônia Ocidental, o grande desafio para a criação avícola é o efeito térmico ambiental, influenciado principalmente pela instabilidade do calor da região, onde são registradas altas temperaturas e umidade. Ao mesmo tempo, o frango surge como fonte de renda. De acordo com Cordeiro et al. (2014), a criação de frangos de corte é uma boa oportunidade de renda para população local, além de exercer menor pressão de desmatamento da floresta, uma vez que depende de menor área de produção. Desta forma o objetivo deste trabalho foi avaliar os efeitos fisiológicos de duas linhagens de frango de corte industrial, determinando qual delas se adapta melhor ao clima de inverno Amazônico.

\section{MATERIAL E MÉTODOS}

O experimento foi conduzido nas instalações experimentais do Setor de avicultura da Universidade Federal do Acre (UFAC) no município de Rio Branco, Estado do Acre. 
O galpão experimental mede $16,0 \mathrm{~m}$ de comprimento por 5,0 $\mathrm{m}$ de largura e é dividido em 32 (trinta) boxes experimentais com dimensões de 2,0 $\mathrm{m} \times 1,0 \mathrm{~m}$ cada. Este está disposto no sentido leste-oeste, com pé direito de 2,8 $\mathrm{m}$, coberto com telhas de alumínio (pintada de branco) e lanternim de fibrocimento. $\mathrm{O}$ piso e as muretas laterais de concreto, pilares e tesoura de madeira, cercado com tela de arame, bem como as divisórias internas.

Nas extremidades do galpão foram instalados ventiladores de parede, em sentido oposto, na altura do pé direito e cortinas. Cada unidade experimental (box) foi equipada com uma lâmpada incandescente de $100 \mathrm{~W}$ de potência, utilizada para o aquecimento na fase inicial. Havia bebedouros e comedouros em cada Box, e a cama era de maravalha com $10 \mathrm{~cm}$ de altura.

O experimento foi realizado nos meses de fevereiro a março de 2016, período este caracterizado por ser o inverno amazônico, por período de 42 dias. Foram utilizados pintos de um dia de duas linhagens, Cobb e Ross, totalizando 280 aves. Os pintos foram sexados, separando machos de fêmeas, distribuídos nas divisórias (box) e estimulados a consumir água e ração. O manejo do alojamento foi realizado de acordo com o indicado por Cotta (2012).

Os pintinhos foram adquiridos de um dia em incubatório idôneo, vacinados no incubatório contra Doença de Marek, Doença de Gumboro e Bouba Aviária. Durante o período experimental, as aves foram vacinadas contra a Doença de Newcastle, aos 14 dias. A ração fornecida foi à base de fubá de milho e farelo de soja, atendendo às necessidades nutricionais em cada etapa de desenvolvimento do frango de corte industrial: fase inicial, crescimento e final.

Aos sete dias de vida, foi selecionada uma ave de cada box para a coleta dos dados fisiológicos. A ave foi identificada com anilhas de plástico. Foram coletados os dados das respostas fisiológicas (frequência respiratória, temperatura de superfície corporal e temperatura cloacal).

O manejo durante o período de criação consistiu na limpeza dos bebedouros e fornecimento ração, duas vezes ao dia, nos horários de oito e 16 horas. A ração era pesada e fornecida nos comedouros durante todo o experimento, sendo: ração inicial (para aves de um a 21 dias de idade), ração de crescimento (para aves de 22 a 35 dias de idade) e ração final (36 a 42 dias de idade).

Para avaliação das respostas fisiológicas foram aferidas a temperatura cloacal, frequência respiratória e temperatura da superfície corporal (cabeça, crista, face, pescoço, peito, sob a asa, perna e penas).

A coleta dos dados foi realizada simultaneamente, utilizando sensor infravermelho digital com precisão de $\pm 0,5{ }^{\circ} \mathrm{C}$, para obtenção dos dados de temperaturas de superfície corporal. Neste procedimento, utilizou-se $10 \%$ das aves de cada boxe (identificadas com anilhas de plástico). Para determinar a temperatura cloacal foi utilizado termômetro clínico digital, com precisão de $\pm 0,1 \stackrel{\circ}{\circ} \mathrm{C}$. A coleta de dados da frequência respiratória, caracterizou-se através do comportamento das aves, utilizando o método visual (mov. $\mathrm{min}^{-1}$ ).

As coletas foram realizadas uma vez por semana, em dois períodos distintos do dia, pela manhã (6 h às $7 \mathrm{~h}$ ) e à tarde (13 h às $14 \mathrm{~h}$ ), horário local, de acordo com metodologia proposta por Costa et al. (2012).

$\mathrm{Na}$ análise do conforto térmico, através das variáveis ambientais, foi utilizado um delineamento em blocos casualizados com sete repetições, em que cada bloco consiste no sexo das aves. O esquema adotado de parcelas subdivididas no tempo, 
em que os efeitos das linhagens foram às parcelas e o período (manhã e tarde) a subparcela.

A análise de variância (ANAVA) foi realizada para verificar possíveis diferenças entre as linhagens em cada período de criação. Foi utilizado o teste de Tukey a 5\%, sendo utilizado o programa Sisvar, descrito por Ferreira (2010).

\section{RESULTADOS E DISCUSSÃO}

$\mathrm{Na}$ Tabela 1 estão apresentados os dados da coleta aos 42 dias de idade dos frangos machos da linhagem Cobb (MC) e fêmeas Cobb (FC), bem como os machos Ross (MR) e fêmeas Ross (FR).

TABELA 1: Temperatura média da cabeça (TCA), da face (TF), do pescoço (TP), da asa (TA), da pena (TPE) da coxa (TCO) e da cloaca (TCL) de machos e fêmeas das linhagens Cobb e Ross.

\begin{tabular}{lccccccc}
\hline Tratamentos & TCA & TF & TP & TA & TPE & TCO & TCL \\
\hline MC & 30,2 & 34,1 & 29,8 & 36,6 & 28,7 & 36,5 & 41,1 \\
FC & 30,9 & 36,0 & 29,4 & 36,5 & 29,0 & 35,5 & 40,3 \\
MR & 31,2 & 35,4 & 30,3 & 34,5 & 28,8 & 34,9 & 40,6 \\
FR & 32,6 & 35,2 & 31,8 & 36,8 & 29,3 & 35,4 & 40,8 \\
\hline CV & 3,28 & 2,10 & 5,98 & 2,45 & 3,36 & 3,38 & 1,42 \\
\hline
\end{tabular}

${ }^{*}$ Médias seguidas de letras distintas, diferem pelo teste de Tukey (5\%).

Os resultados das coletas, feitas a cada sete dias, não apresentaram diferença significativa $(P>0,05)$ para as temperaturas de: cabeça, face, pescoço, asa, pena, coxa e cloaca. Os dados apresentados na Tabela 2 mostram os resultados das coletas de temperatura de peito e do dorso.

TABELA 2: Temperatura média do peito e do dorso de machos e fêmeas das linhagens Cobb e Ross.

\begin{tabular}{|c|c|c|c|c|c|c|}
\hline \multirow{3}{*}{ Tratamentos } & \multicolumn{5}{|c|}{ Peito } & \multirow[b]{3}{*}{42} \\
\hline & \multicolumn{5}{|c|}{ Dias } & \\
\hline & 7 & 14 & 21 & 28 & 35 & \\
\hline$M C$ & 33,26 & $36,34 b$ & 35,25 & 35,33 & 31,98 & 30,10 \\
\hline $\mathrm{FC}$ & 32,74 & $34,47 a$ & 34,01 & 34,66 & 31,50 & 29,80 \\
\hline MR & 33,63 & $34,85 a b$ & 33,93 & 34,91 & 32,01 & 30,30 \\
\hline $\mathrm{FR}$ & 34,00 & $35,13 a b$ & 34,71 & 34,90 & 30,94 & 31,10 \\
\hline \multirow[t]{2}{*}{$\mathrm{CV}$} & 4,87 & 5,56 & 7,84 & 5,58 & 5,33 & 5,65 \\
\hline & \multicolumn{5}{|c|}{ Dorso } & \\
\hline$\overline{M C}$ & 33,37 & 34,87 & $35,77 b$ & $35,21 b$ & $30,77 a$ & $28,40 a$ \\
\hline $\mathrm{FC}$ & 33,58 & 36,01 & $33,96 a$ & $33,78 a$ & $31,17 a b$ & $29,90 a b$ \\
\hline MR & 33,54 & 35,18 & $34,94 a b$ & $35,24 b$ & $34,24 b$ & $34,70 b$ \\
\hline FR & 33,70 & 34,96 & $34,27 a b$ & $33,45 a$ & $31,42 a b$ & $30,00 a b$ \\
\hline $\mathrm{CV}$ & 2,63 & 3,37 & 3,49 & 2,69 & 7,13 & 4,90 \\
\hline
\end{tabular}

*Médias seguidas de letras distintas, diferem pelo teste de Tukey (5\%).

Com relação ao peito houve diferença significativa $(p<0,05)$ somente entre machos e fêmeas da linhagem Cobb aos 14 dias, não havendo diferença em relação à linhagem Ross. 
Já em relação à temperatura de dorso, houve diferença significativa na linhagem Cobb aos 21 dias, sendo que o macho apresentou temperatura maior que a fêmea da mesma linhagem. Aos 28 dias, os machos das duas linhagens apresentaram temperaturas maiores $(p<0,05)$ que as das fêmeas. Posteriormente, aos 35 e 42 dias o macho Ross apresentou maior temperatura somente em relação ao macho da linhagem Cobb. Na Tabela 3, estão os dados de frequência respiratória dos frangos machos e fêmeas das linhagens Cobb e Ross.

TABELA 3: Frequência respiratória média de frangos machos e fêmeas das linhagens Cobb e Ross.

\begin{tabular}{lcccccc}
\hline Tratamentos & $\mathbf{7}$ Dias \\
\cline { 2 - 7 } & $\mathbf{7}$ & $\mathbf{1 4}$ & $\mathbf{2 1}$ & $\mathbf{2 8}$ & $\mathbf{3 5}$ & $\mathbf{4 2}$ \\
\hline MC & 44,00 & $41,14 \mathrm{ab}$ & 41,71 & 42,28 & 41,14 & 43,45 \\
FC & 42,85 & $44,00 \mathrm{ab}$ & 48,57 & 44,57 & 43,43 & 45,13 \\
MR & 40,00 & $40,66 \mathrm{a}$ & 46,86 & 43,43 & 48,57 & 44,00 \\
FR & 42,85 & $53,71 \mathrm{~b}$ & 45,71 & 53,14 & 54,14 & 42,89 \\
\hline CV & 17,73 & 18,70 & 21,71 & 19,90 & 15,17 & 18,65 \\
\hline
\end{tabular}

${ }^{*}$ Médias seguidas de letras distintas, diferem pelo teste de Tukey (5\%).

Somente houve diferença significativa aos 14 dias, as fêmeas Ross apresentaram uma frequência maior que a dos machos. De acordo com Cassuce (2011), em conclusão relatou que as temperaturas de conforto térmico ideais para a linhagem Cobb são de $31^{\circ} \mathrm{C}$ na primeira semana, entre 26,3 a $27^{\circ} \mathrm{C}$ na segunda semana e entre 22 a $23^{\circ} \mathrm{C}$ na terceira semana, sendo que, as temperaturas iniciais influenciam diretamente no desempenho produtivo das aves.

Segundo Nascimento et al. (2011), em estudo com Cobb, enfatizaram a importância de conhecer as regiões de conforto térmico da linhagem, afim de a estrutura da granja corrobore com o desempenho do animal. Em estudo sob ambientes controlados com a linhagem Ross, Oliveira et al. (2006) relatam a ação prejudicial da temperatura e umidade relativa alta $\left(32{ }^{\circ} \mathrm{C}\right.$ e $\left.75 \%\right)$. No presente trabalho, apesar de algumas diferenças quanto ao dorso, peito, e frequência respiratória, ambas as linhagens apresentaram desempenhos semelhantes ao clima de inverno amazônico.

Em contrapartida, o trabalho de Barbosa et al. (2016), com diferentes linhagens, no estado do Acre, mostram diferenças significativas de temperatura média corporal entre as linhagens estudadas e também entre os sexos dos frangos, afetando o rendimento final das aves. Assim, deve-se prezar por instalações que supram as necessidades de conforto das linhagens, a fim de não prejudicar seu desempenho produtivo.

De acordo com Ponciano (2011), quando a genética, as instalações, a nutrição, o manejo e a sanidade são planejados de forma satisfatória, as aves terão ótimos rendimentos quanto ao produto final. A densidade das aves por metro quadrado, também deve ser observada, para não haver estresse calórico (NAZARENO et al., 2009).

\section{CONCLUSÃO}

Conclui-se que as linhagens de frangos industriais estudadas e criadas sob condição de inverno Amazônico, possuem respostas fisiológicas semelhantes. 


\section{REFERÊNCIAS}

BARBOSA, M. de J. S. da S. Efeito do ambiente térmico sobre as respostas fisiológicas e produtivas de frangos de corte de linhagem caipira criados em condições de inverno Amazônico. 2016. 75 f. Dissertação (Mestrado em Ciência Animal) - Universidade Federal do Acre, Rio Branco. 2016.

CASSUCE, D. C. Determinação das faixas de conforto térmico para frangos de diferentes idades criados no Brasil. 2011. 103 f. Tese (Doctor Scientiae) Universidade Federal de Viçosa, Minas Gerais. 2011.

CORDEIRO, M. B.; FREITAS; H. J.; AQUINO, E. O.; SOUSA, E. M. Avaliação do estresse térmico em frangos caipiras criados em condições climáticas do Estado do Acre. Enciclopédia Biosfera, Goiânia, v.10, n. 18, p. 1666-1864. 2014. Disponível em:

http://www.conhecer.org.br/enciclop/2014b/AGRARIAS/avaliacao\%20do\%20estress e.pdf>.

COSTA, J. H. S.; SARAIVA, E. P.; SANTOS, L. F. D. Efeito do ambiente sobre indicadores fisiológicos na produção de frangos de corte. Revista Verde, Mossoró, v. $7, \quad$ n. 4, p. 54-58. 2012. Disponível em: < www.gvaa.com.br/revista/index.php/RVADS/article/download/1395/1508>.

COTTA, T. Frangos de corte: criação, abate e comercialização. 2. ed. Viçosa, Minas Gerais: Aprenda Fácil Editora, 2012. 243 p.

FERREIRA, D.F. Sisvar sitema de análise de variância. Lavras: Ufla, 2010.

LOPES, J. C. O.; RIBEIRO, M. N.; LIMA, V. B. S. Estresse por calor em frangos de corte. Nutritime, Viçosa, vol. 12, n. 06, p. 4478-4487, 2015. Disponível em: <http://www.nutritime.com.br/arquivos_internos/artigos/352_-_4478-4487_-

NRE_12-6_nov-dez_2015.pdf>.

MACARI, M.; FURLAN, R. L.; GONZALES, E. Fisiologia aviária aplicada a frangos de corte. 2 ed. Jaboticabal: FUNEP, 2002. 375 p.

NASCIMENTO, G. R.; PEREIRA, D. F.; NAAS, I. A.; RODRIGUES, L. H. Índice fuzzy de conforto térmico para frangos de corte. Engenharia Agrícola, Jaboticabal, v. 31, n. 2, p. 219-229. 2011. Disponível em: <http://dx.doi.org/10.1590/S010069162011000200002> . doi: 10.1590/S0100-69162011000200002.

NAZARENO, C. A.; PANDORFI, H.; ALMEIDA, L. P. G.; GIONGO, R. P.; PEDROSA, M. R. E.; GUISELINI, C. Avaliação do conforto térmico e desempenho de frangos de corte sob regime de criação diferenciado. Revista Brasileira de Engenharia Agrícola e Ambiental, Campina Grande, v. 13, n. 6, p. 802-808. 2009. Disponível em: http://www.scielo.br/pdf/rbeaa/v13n6/v13n6a20.pdf>.

OLIVEIRA, R. F. M.; DONZELE, J. L.; ABREU, M. L. T.; FERREIRA, R. A.; VAZ, R. G. M. V.; CELLA, P. G. Efeitos da temperatura e da umidade relativa sobre o desempenho e o rendimento de cortes nobres de frangos de corte de 1 a 49 dias de idade. Revista 
Brasileira de Zootecnia, Piracicaba, v. 35, n. 3, p. 797-803, 2006. Disponível em: < http://www.scielo.br/scielo.php?script=sci_arttext\&pid=S1516-

$35982006000300023 \&$ Ing=pt\&tlng=pt>. doi: $10.1590 /$ S1516-35982006000300023.

RODRIGUES, W. O. P.; GARCIA, R. G.; NÄÄS, I. de A. R; ROSA C. O. da; CALDARELLI, C. E. Evolução da avicultura de corte no Brasil. Enciclopédia Biosfera, Goiânia, v. 10, n. 18, p. 1666-1864. 2014. Disponível em: < http://www.conhecer.org.br/enciclop/2014a/AGRARIAS/EVOLUCAO.pdf>.

PONCIANO, P. F. Predição do desempenho produtivo e temperatura retal de frangos de corte durante os primeiros 21 dias de vida. 2011. $97 \mathrm{f}$. Dissertação (mestrado em Engenharia Agrícola) - Programa de Pós-Graduação, Universidade Federal de Lavras, Lavras, 2011. 